In the second experiment, 4 protein sequences were compared in order to determine whether the protein level during fattening was related to the post-weaning level (interaction?). The four sequences were chosen so as to represent the 4 currently encountered possibilities (high-high, i.e. 22-18 p. 100 crude protein, high-low, 22-15 p. 100, low-high, 18-18 p. 100, low-low, $18-15$ p. 100).

Post-weaning protein level had no significant subsequent effect during fattening, either on growth or body composition.

No statistically significant interaction between post-weaning and fattening protein levels was evidenced with the 4 sequencies of the second experiment.

Thus, the protein sequence to be chosen should be that supplying optimum growth performance during each period, i.e. 22-18 p. 100. However the farmer (rearer/feeder) manufacturing the feeds himself might prefer to make one only feed. He should then choose sequence 18-18 giving similar results as sequence 22-18.

\title{
Influence of management system (separation or mixing of sexes) on the performance of castrated male pigs and females
}

\author{
F. GROSJEAN *, B. CHAMBON **, J. CASTAING ***, J. CHAUVEL ****, \\ P. LATIMIER *****, D. LE MEUR $* * * * * *$, P. QUEMERE $* * * * * * *$ \\ *I.T.C.F., ** Stagiaire à l'I.T.C.F., *** A.G.P.M., **** I.T.P., \\ ***** E.D.E. 22, ***** E.D.E. 29, ******** S.E.R.E.P. \\ (France)
}

Five experiments involving 208 castrated males and 108 females were carried out in order to determine whether the mixing of sexes affects the performance of the animals.

All animals were fed according to the same feeding schedule based upon live weight. Maximum level of restriction was $7945 \mathrm{kcal}$ D.E./day from $60 \mathrm{~kg}$ during 2 experiments and $9000 \mathrm{kcal}$ D.E./ day from $70 \mathrm{~kg}$, during 3 experiments.

Each experiment involved 3-5 replications and each replication involved 4 types of pens; 1 with castrated males, 1 with females and 2 with an equal number of males and females together.

During the first analysis, we compared (for each criterion) the average growth and slaughter performance of males and females kept separately, and those of the group of males and females mixed together. During the second analysis, we measured the effect of mixing upon each sex.

The results of these 5 trials show that the management system did not significantly affect either the growth criterion (growth rate, food conversion ratio) or the carcass traits (dressing percentage, side backfat thickness and grading).

Mixing the animals seemed to favour the growth of castrated males more than that of the females, but this was probably due to the domination of the males at the trough. However, this effect was not very clear as regards the carcass composition of these animals.

\section{A comparative study concerning the utilization of pellets of different diameters by the weaned piglet}

\author{
O. LAVOREL, J. FEKETE, M. LEUILLET \\ I.T.C.F., 8, avenue du Président-Wilson, F 75116 Paris
}

Four different physical forms of post-weaning feeds (1st and 2nd age) were compared : dry flour, pellets of $2.5,3$ and $5 \mathrm{~mm}$ diameter. 